\title{
Enhancement of auditory fear conditioning after housing in a complex environment is attenuated by prior treatment with amphetamine
}

\author{
Lisa A. Briand, ${ }^{1}$ Terry E. Robinson, ${ }^{1,2}$ and Stephen Maren ${ }^{1,2,3}$ \\ ${ }^{1}$ Neuroscience Program and ${ }^{2}$ Department of Psychology, University of Michigan, Ann Arbor, Michigan 48109, USA
}

\begin{abstract}
Prior exposure to drugs of abuse has been shown to occlude the structural plasticity associated with living in a complex environment. Amphetamine treatment may also occlude some cognitive advantages normally associated with living in a complex environment. To test this hypothesis we examined the influence of prior exposure to amphetamine on fear conditioning in rats housed in either a standard or complex environment. Housing in a complex environment facilitated fear learning to an auditory conditioned stimulus (CS), but not to the training context, relative to animals housed singly or in a social group. Prior treatment with amphetamine eliminated this effect. These results indicate that living in a complex environment facilitates conditional freezing to an auditory CS, and that this effect is abolished by pretreatment with amphetamine.
\end{abstract}

Housing in a relatively complex environment ("environmental enrichment") is known to alter the structure of dendrites (i.e., induce structural plasticity) in a variety of brain regions, and to also influence subsequent learning and memory. The first evidence for structural changes in the brain as a result of living in a complex environment was provided by Rosenzweig and colleagues in the 1960s, who reported that animals living in a complex environment showed increased cortical weight compared with animals in standard laboratory cages (Rosenzweig et al. 1962). Since that time, there have been many studies documenting a number of brain changes in rats living in a complex environment, including increases in cerebral volume, dendritic spine density and number, long-term potentiation (LTP), resistance to neural insult, and synaptic connectivity (Rosenzweig and Bennett 1969; Rosenzweig et al. 1969; Greenough et al. 1985, 1986; Green and Greenough 1986; Kolb and Gibb 1991). Although these changes have been found in the cerebral cortex and other brain regions, the focus in many of these studies has been on the hippocampus. In addition to modifying hippocampal morphology, complex housing also enhances performance on a number of hippocampal-dependent learning tasks. The most welldocumented augmentation of learning after complex housing is in spatial tasks such as the Morris water maze and Hebb-Williams maze (Pham et al. 1999; Kobayashi et al. 2002). However, there is also evidence that environmental enrichment enhances Pavlovian fear conditioning in mice (Rampon et al. 2000; Duffy et al. 2001; Tang et al. 2001).

Although these examples of experience-dependent plasticity are clearly advantageous, this is not true of all forms of experience-dependent plasticity. Repeated treatment with psychostimulant drugs, for example, also leads to an increase in dendritic branching and spine density in a number of brain regions, which is thought to be related to the development of behavioral sensitization (Robinson and Kolb 1997, 1999, 2004; Robinson et al. 2001; Li et al. 2004). However, treatment with amphetamine or cocaine has also been shown to occlude the ability of subsequent exposure to a complex environment to alter

\section{${ }^{3}$ Corresponding author.}

E-mail maren@umich.edu; fax (734) 763-7480.

Article published online ahead of print. Article and publication date are at http://www.learnmem.org/cgi/doi/10.1101/lm.95905. dendritic structure (Kolb et al. 2003). This ability of drugs of abuse to occlude environment-dependent structural changes suggests that it is possible that drug experience prior to exposure to a complex environment will also modulate the subsequent effect of a complex environment on learning and memory.

The present experiments were designed to determine whether living in a complex environment for 3 mo modulates associative learning in a Pavlovian fear-conditioning paradigm in rats, and whether a prior history of amphetamine exposure would modulate environmental effects on learning. In the first experiment, male Sprague Dawley rats (Harlan) were housed for 3 mo in either individual plastic hanging cages $(20 \times 23 \times 20$ $\mathrm{cm})$ in groups of three in rectangular plastic cages $(20 \times 43 \times 20$ $\mathrm{cm})$, or in groups of 12 in stainless-steel monkey cages $(61 \times 61 \times 72 \mathrm{~cm})$. Animals were then conditioned with four pairings of an auditory conditional stimulus (CS) and a footshock unconditioned stimulus (US), and freezing served as a measure of conditioned fear. After this, we examined the effect of environmental complexity on both contextual and cued fear conditioning. In the second experiment, rats were first treated repeatedly with amphetamine or saline (21 consecutive days of $4.0 \mathrm{mg} / \mathrm{kg}$ with intermittent doses of $0.5 \mathrm{mg} / \mathrm{kg}$ to measure the extent of psychomotor sensitization) and then placed in a complex environment or left in standard laboratory cages for $3 \mathrm{mo}(n=12$ for each of the four groups). They then underwent a Pavlovian fearconditioning protocol and were tested for both contextual and cued fear learning. We report that prior exposure to amphetamine attenuated the enhanced fear conditioning otherwise associated with living in a complex environment.

To determine the effects of environmental complexity on Pavlovian fear conditioning, we first examined immediate postshock freezing behavior on the conditioning day following four tone (30 sec; $80 \mathrm{~dB} ; 2 \mathrm{kHz}$ )-footshock ( $2 \mathrm{sec} ; 1 \mathrm{~mA}$ ) pairings (Fig. $1 \mathrm{~A})$. There were no group differences in either unconditional freezing prior to shock presentation or during the 1-min intervals immediately after shock. In contrast, housing condition modulated long-term fear memory, as shown in Figure 1B. Housing in a complex environment led to more robust freezing to the auditory CS than seen in animals housed individually or socially $\left(F_{(2,224)}=8.4 ; P=0.001\right)$. This difference was most prominent at the later time points in the test, with the complex group showing a prolonged freezing response (group-minute interaction, 
A

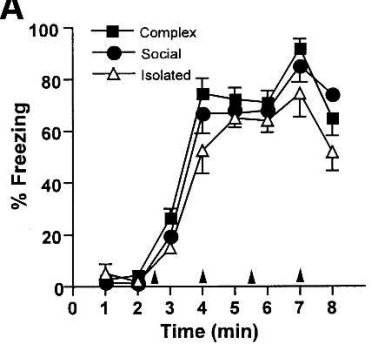

B

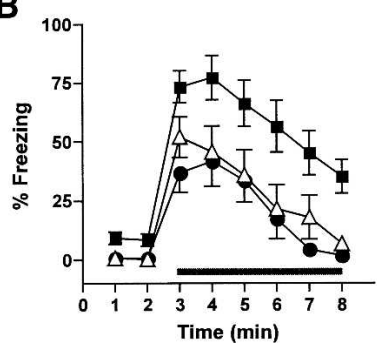

C

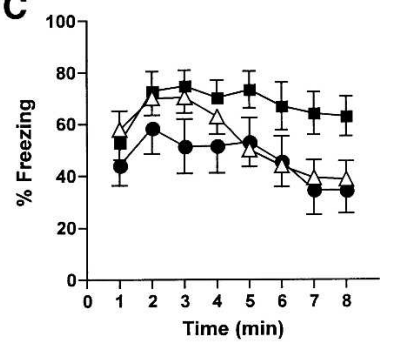

plex environment is more prominent for auditory fear conditioning. Although contextual fear is traditionally thought to be both hippocampal and amygdala dependent and cued fear purely amygdala dependent, recent studies have shown hippocampal involvement in cued fear as well. Although there is some evidence that dorsal hippocampal lesions affect auditory fear (Maren et al. 1997), the evidence is much stronger for the involvement of the ventral hippocampus. Electrolytic lesions of the ventral hippocampus disrupt auditory fear conditioning (Trivedi and Coover 2004), and neurotoxic lesions of the ventral hippocampus have been shown to disrupt auditory fear conditioning while leaving contextual fear intact (Maren 1999; Richmond et al. 1999; Maren and Holt 2004). It is possible, therefore, that

$\left.F_{(14,224)}=1.825 ; P<0.05\right)$. No differences were observed between the socially and individually housed animals, indicating the effect of a complex environment was not due merely to social interaction (Fig. 1B). Only a trend toward significance was seen between the groups in contextual freezing, although an interaction was present, indicating that the animals living in a complex environment showed a prolonged freezing response at the later time points (group-minute interaction, $F_{(14,224)}=1.84 ; P<0.05$ ) (Fig. 1C).

In Experiment 2, prior amphetamine treatment, using a regimen that produced robust behavioral sensitization (Fig. 2), attenuated the effect of environmental complexity on cued fear conditioning (Fig. 3A). Rats in the Complex/SAL group exhibited a more robust freezing response than the Social/SAL, Complex/ $\mathrm{AMPH}$, and Social/AMPH groups (housing-drug interaction, $\left.F_{(1,308)}=4.8 ; P<0.05\right)$ (Fig. 3A). No differences were seen between any of the groups in contextual freezing (Fig. 3B).

As the animals in the previous experiment were removed from their respective environments and tested while all in social housing, this experiment replicated the previous results without this housing switch prior to testing. The drug administration protocol resulted in robust psychomotor sensitization in the amphetamine group $(n=12)$ [mean \pm SEM peak beam breaks, first test session, $75.8 \pm 8.7$ vs. last test session, $139.2 \pm 22.5$, $t_{(9)}=3.173, P=0.01$ ] (data not shown). Just as in Experiment 2, prior amphetamine attenuated cued fear conditioning in animals housed in a complex environment $\left(F_{(1,112)}=6.2 ; P<0.05\right)$ (Fig. $4 \mathrm{~A})$. No differences were seen in contextual fear conditioning (Fig. 4B).

Housing in a relatively complex environment facilitated Pavlovian fear conditioning, and the effect of environment on conditioned fear was much stronger for auditory fear than contextual fear. This is inconsistent with previous reports that have found equivalent effects of environmental enrichment on auditory and contextual fear (Duffy et al. 2001; Tang et al. 2001). As all of the previous studies used mice, it is possible that the difference is due to the species; however, it is more likely due to differences in the protocol. In previous studies, a single CS-US pairing was used, whereas we used multiple conditioning trials. The isolated and socially housed animals may use this additional time in the conditioning context for consolidation of the contextual fear memory, while the complex-housed animals exhibit a ceiling effect.

Despite this potential effect of housing context on contextual fear conditioning, our data indicate that the effect of a com- environmental complexity modifies the ventral hippocampus in a way that allows for the enhancement of cued fear while having only a slight effect on contextual fear.

Our second experiment indicates that prior exposure to amphetamine attenuates the ability of later experience in a complex environment to modulate fear learning. Prior exposure to stimulant drugs has also been shown to limit the structural plasticity associated with living in a complex environment (Kolb et al. 2003). It is possible, therefore, that prior exposure to amphetamine occluded the effect of experience in a complex environment to facilitate fear learning because it limited the experiencedependent structural plasticity usually associated with living in a complex environment. This idea is supported by a recent study using nicotine (Gonzalez et al. 2005). Nicotine increases dendritic arborization in the motor cortex, and when given concurrently with training, improves performance on a food retrieval task. Despite these acute improvements, learning of a subsequent skilled reaching task was impaired as a result of previous nicotine treatment, and prior treatment with nicotine also occluded the structural changes in motor cortex typically associated with learning a skilled reaching task.

Although stimulant drugs can impair plasticity under certain circumstances, other studies show that stimulant drugs can augment experience-dependent plasticity. For example, a low dose of methamphetamine administered prior to 2-h daily expe-

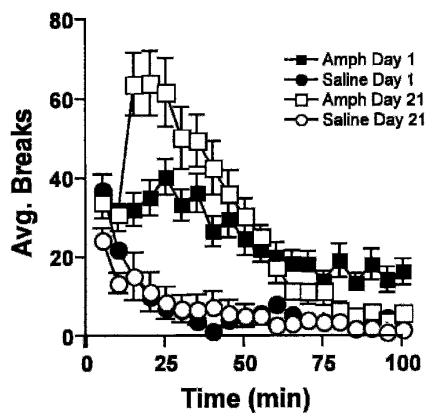

Figure 2. Psychomotor sensitization mean $( \pm$ SEM) beam breaks per 5-min bin. Amphetamine-treated animals showed significantly higher locomotor activity on day 21 (ㅁ) as compared with day 1 ( $(\square)$ [mean \pm SEM peak beam breaks, first test session, $57.6 \pm 4.2$ vs. last test session, $\left.83.4 \pm 7.4, t_{(24)}=2.919, P<0.01\right]$. No differences were seen between saline-treated animals on day 21 ( $)$ compared with day $1(\bullet)$. 
rience with a complex environment leads to an increase in cortical weight that is greater in animals that received the drug during a different portion of the day while in their home cages (Bennett et al. 1973). The conjunction of both experience in a complex environment and low-dose stimulant drugs has been shown to increase recovery following brain injury more than either treatment alone (Feeney et al. 1982). Similarly, WalkerBatson et al. (2001) reported that amphetamine in conjunction with speech therapy leads to greater recovery from aphasia.

The ability of drugs of abuse to limit future experiencedependent structural plasticity has been shown in the nucleus accumbens as well as the parietal cortex (Kolb et al. 2003). The amygdala and the ventral hippocampus, however, are the key brain areas involved in cued fear conditioning (Maren and Holt 2004, Trivedi and Coover 2004). While there are synaptic connections between the nucleus accumbens and both the amygdala and the ventral hippocampus that could be responsible for our behavioral interaction, it would be useful to elucidate whether structural changes are occurring in these brain areas as well. Environmental complexity has been shown to alter dendritic structure in the nucleus accumbens, caudate-putamen, and hippocampus (Green and Greenough 1986; Sirevaag et al. 1988; Comery et al. 1996; Kolb et al. 2003). The effect of environmental complexity on the hippocampus is particularly well documented, including alterations in dendritic patterning and increases in dendritic branching and dendritic spines (Kelche and Will 1982; Juraska et al. 1989). To our knowledge, although morphological studies of the amygdala following housing in a complex environment have not been reported, housing condition does influence the ability of fear conditioning to increase gene expression in the amygdala (Nikolaev et al. 2002). In this study, animals that were housed in an enriched environment showed a decrease in Fos-positive cells in the amygdaloid-striatal transition area after conditioning. Furthermore, experience-dependent remodeling of the amygdala has been observed following chronic stress (Vyas et al. 2002, 2003). Taken together, these studies suggest that the dendritic morphology in the hippocampus and the amygdala may also be altered by environmental enrichment, and potentially modulated by drug exposure.

Numerous studies have documented neuropsychological deficits in human amphetamine and cocaine addicts (Rogers and Robbins 2001). Typically, these behavioral and cognitive deficits have been attributed to either a neurotoxic or "functional" lesion produced by drug exposure. However, when combined with studies showing that exposure to drugs of abuse can occlude subsequent structural plasticity, our results suggest an alternative
A

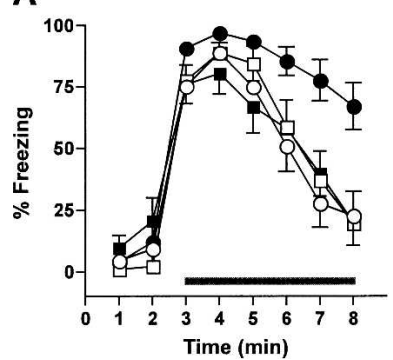

B

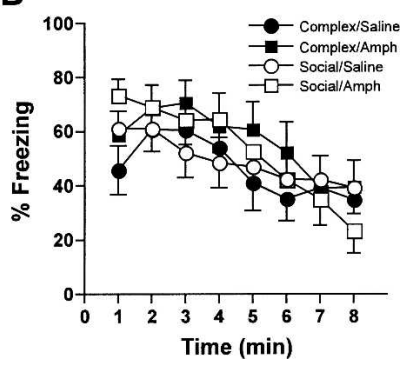

Figure 3. Effect of prior sensitization on cued and contextual freezing. $(A)$ Cued fear conditioning (conducted $48 \mathrm{~h}$ after conditioning). Prior amphetamine attenuated the effect of environmental complexity on cued freezing. Mean ( \pm SEM) percent time freezing during the 8-min testing session (bar indicates 6-min continuous tone presentation). (B) Contextual fear conditioning (conducted $24 \mathrm{~h}$ after conditioning). No differences were seen among the groups in contextual freezing. Mean $( \pm$ SEM) percent time freezing during the 8-min testing session.
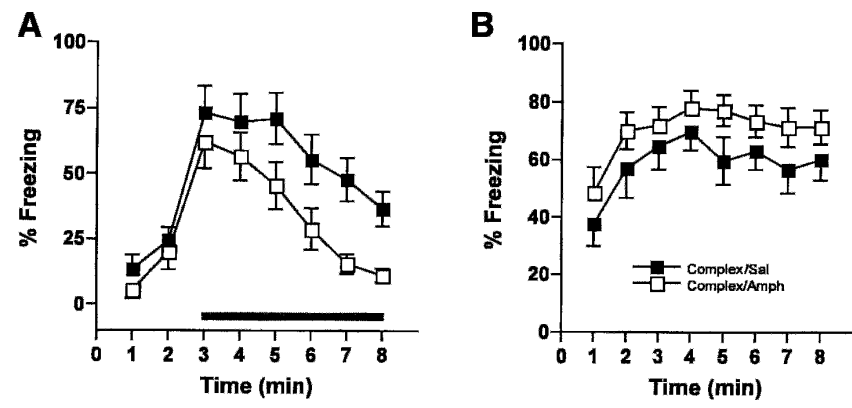

Figure 4. Replication. Prior amphetamine blocked the effect of complexity on cued fear. $(A)$ Cued fear conditioning (conducted $48 \mathrm{~h}$ after conditioning). Prior amphetamine sensitization decreased the effect of housing in a complex environment. Mean ( \pm SEM) percent time freezing during the 8-min testing session (bar indicates 6-min continuous tone presentation). (B) Contextual fear conditioning (conducted $24 \mathrm{~h}$ after conditioning). No differences were seen among the groups in contextual freezing. Mean $( \pm$ SEM) percent time freezing during the 8-min testing session.

hypothesis, i.e., exposure to drugs of abuse may limit future experience-dependent plasticity.

\section{Acknowledgments}

Supported by grant RO1MH065961 to S.M. from the National Institutes of Health and grant RO1 DA13398 to T.E.R. from the National Institute on Drug Abuse (NIDA). T.E.R. was also supported by a Senior Scientist Award from NIDA (KO5 DA00473). L.B. was supported by a Regents' Fellowship from the Horace H. Rackham School of Graduate Studies at the University of Michigan.

\section{References}

Bennett, E.L., Rosenzweig, M.R., and Wu, S.Y.C. 1973. Excitant and depressant drugs modulate effects of environment on brain weight and cholinesterases. Psychopharmacologia 33: 309-328.

Comery, T.A., Stamoudis, C.X., Irwin, S.A., and Greenough, W.T. 1996. Increased density of multiple-head dendritic spines on medium-sized spiny neurons of the striatum in rats reared in a complex environment. Neurobiol. Learn. Mem. 66: 93-96.

Duffy, S.N., Craddock, K.J., Abel, T., and Nguyen, P.V. 2001. Environmental enrichment modifies the PKA-dependence of hippocampal LTP and improves hippocampus-dependent memory. Learn. Mem. 8: 26-34.

Feeney, D.M., Gonzalez, A., and Law, W.A. 1982. Amphetamine, haloperidol, and experience interact to affect rate of recovery after motor cortex injury. Science 217: 855-857.

Gonzalez, C.L., Gharbawie, O.A., Whishaw, I.Q., and Kolb, B. 2005. Nicotine stimulates dendritic arborization in motor cortex and improves concurrent motor skill but impairs subsequent motor learning. Synapse 55: 183-191.

Green, E.J. and Greenough, W.T. 1986. Altered synaptic transmission in dentate gyrus of rats reared in complex environments: Evidence from hippocampal slices maintained in vitro. J. Neurophysiol. 55: 739-750.

Greenough, W.T., Hwang, H.M., and Gorman, C. 1985. Evidence for active synapse formation or altered postsynaptic metabolism in visual cortex of rats reared in complex environments. Proc. Natl. Acad. Sci. 82: 4549-4552.

Greenough, W.T., McDonald, J.W., Parnisari, R.M., and Camel, J.E. 1986. Environmental conditions modulate degeneration and new dendrite growth in cerebellum of senescent rats. Brain Res. 380: $136-143$.

Juraska, J.M., Fitch, J.M., and Washburne, D.L. 1989. The dendritic morphology of pyramidal neurons in the rat hippocampal CA3 area. II. Effects of gender and the environment. Brain Res. 479: 115-119.

Kelche, C. and Will, B. 1982. Effects of postoperative environments following dorsal hippocampal lesions on dendritic branching and spines in rat occipital cortex. Brain Res. 245: 107-115.

Kobayashi, S., Ohashi, Y., and Ando, S. 2002. Effects of enriched environments with different durations and starting times on learning capacity during aging in rats assessed by a refined procedure of the Hebb-Williams maze task. J. Neurosci. Res. 
70: $340-346$

Kolb, B. and Gibb, R. 1991. Environmental enrichment and cortical injury: Behavioral and anatomical consequences of frontal cortex lesions. Cereb. Cortex 1: 189-198.

Kolb, B., Gorny, G., Li, Y., Samaha, A.N., and Robinson, T.E. 2003. Amphetamine or cocaine limits the ability of later experience to promote structural plasticity in the neocortex and nucleus accumbens. Proc. Natl. Acad. Sci. 100: 10523-10528.

Li, Y., Acerbo, M.J., and Robinson, T.E. 2004. The induction of behavioural sensitization is associated with cocaine-induced structural plasticity in the core (but not shell) of the nucleus accumbens. Eur. J. Neurosci. 20: 1647-1654.

Maren, S. 1999. Neurotoxic or electrolytic lesions of the ventral subiculum produce deficits in the acquisition and expression of Pavlovian fear conditioning in rats. Behav. Neurosci. 113: 283-290.

Maren, S. and Holt, W.G. 2004. Hippocampus and Pavlovian fear conditioning in rats: Muscimol infusions into the ventral, but not dorsal, hippocampus impair the acquisition of conditional freezing to an auditory conditional stimulus. Behav. Neurosci. 118: 97-110.

Maren, S., Aharonov, G., and Fanselow, M.S. 1997. Neurotoxic lesions of the dorsal hippocampus and Pavlovian fear conditioning in rats. Behav. Brain Res. 88: 261-274.

Nikolaev, E., Kaczmarek, L., Zhu, S.W., Winblad, B., and Mohammed, A.H. 2002. Environmental manipulation differentially alters c-Fos expression in amygdaloid nuclei following aversive conditioning. Brain Res. 957: 91-98.

Pham, T.M., Soderstrom, S., Winblad, B., and Mohammed, A.H. 1999. Effects of environmental enrichment on cognitive function and hippocampal NGF in the non-handled rats. Behav. Brain Res. 103: $63-70$.

Rampon, C., Tang, Y.P., Goodhouse, J., Shimizu, E., Kyin, M., and Tsien, J.Z. 2000. Enrichment induces structural changes and recovery from nonspatial memory deficits in CA1 NMDAR1-knockout mice. Nat. Neurosci. 3: 238-244.

Richmond, M.A., Yee, B.K., Pouzet, B., Veenman, L., Rawlins, J.N., Feldon, J., and Bannerman, D.M. 1999. Dissociating context and space within the hippocampus: Effects of complete, dorsal, and ventral excitotoxic hippocampal lesions on conditioned freezing and spatial learning. Behav. Neurosci. 113: 1189-1203.

Robinson, T.E. and Kolb, B. 1997. Persistent structural modifications in nucleus accumbens and prefrontal cortex neurons produced by previous experience with amphetamine. J. Neurosci. 17: 8491-8497.

- 1999. Alterations in the morphology of dendrites and dendritic spines in the nucleus accumbens and prefrontal cortex following repeated treatment with amphetamine or cocaine. Eur. J. Neurosci. 11: $1598-1604$.
2004. Structural plasticity associated with exposure to drugs of abuse. Neuropharmacology 47: 33-46.

Robinson, T.E., Gorny, G., Mitton, E., and Kolb, B. 2001. Cocaine self-administration alters the morphology of dendrites and dendritic spines in the nucleus accumbens and neocortex. Synapse 39: 257-266.

Rogers, R.D. and Robbins, T.W. 2001. Investigating the neurocognitive deficits associated with chronic drug misuse. Curr. Opin. Neurobiol. 11: $250-257$.

Rosenzweig, M.R. and Bennett, E.L. 1969. Effects of differential environments on brain weights and enzyme activities in gerbils, rats, and mice. Dev. Psychobiol. 2: 87-95.

Rosenzweig, M.R., Krech, D., Bennett, E.L., and Diamond, M.C. 1962. Effects of environmental complexity and training on brain chemistry and anatomy: A replication and extension. J. Comp. Physiol. Psychol. 55: 429-437.

Rosenzweig, M.R., Bennett, E.L., Diamond, M.C., Wu, S.Y., Slagle, R.W., and Saffran, E. 1969. Influences of environmental complexity and visual stimulation on development of occipital cortex in rat. Brain Res. 14: 427-445.

Sirevaag, A.M., Black, J.E., Shafron, D., and Greenough, W.T. 1988. Direct evidence that complex experience increases capillary branching and surface area in visual cortex of young rats. Brain Res. 471: $299-304$

Tang, Y.P., Wang, H., Feng, R., Kyin, M., and Tsien, J.Z. 2001. Differential effects of enrichment on learning and memory function in NR2B transgenic mice. Neuropharmacology 41: 779-790.

Trivedi, M.A. and Coover, G.D. 2004. Lesions of the ventral hippocampus, but not the dorsal hippocampus, impair conditioned fear expression and inhibitory avoidance on the elevated T-maze. Neurobiol. Learn. Mem. 81: 172-184.

Vyas, A., Mitra, R., Shankaranarayana Rao, B.S., and Chattarji, S. 2002 Chronic stress induces contrasting patterns of dendritic remodeling in hippocampal and amygdaloid neurons. J. Neurosci. 22: 6810-6818.

Vyas, A., Bernal, S., and Chattarji, S. 2003. Effects of chronic stress on dendritic arborization in the central and extended amygdala. Brain Res. 965: 290-294.

Walker-Batson, D., Curtis, S., Natarajan, R., Ford, J., Dronkers, N., Salmeron, E., Lai, J., and Unwin, D.H. 2001. A double-blind, placebo-controlled study of the use of amphetamine in the treatment of aphasia. Stroke 32: 2093-2098.

Received April 1, 2005; accepted in revised form August 18, 2005. 


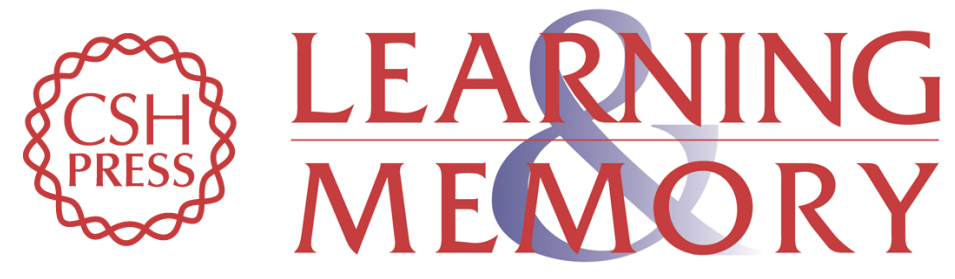

\section{Enhancement of auditory fear conditioning after housing in a complex environment is attenuated by prior treatment with amphetamine}

Lisa A. Briand, Terry E. Robinson and Stephen Maren

Learn. Mem. 2005, 12:

Access the most recent version at doi:10.1101//m.95905

References This article cites 34 articles, 7 of which can be accessed free at: http://learnmem.cshlp.org/content/12/6/553.full.html\#ref-list-1

License

Email Alerting

Receive free email alerts when new articles cite this article - sign up in the box at the Service top right corner of the article or click here. 